\title{
Influencia ideológica. La reconstrucción de un concepto: La Revolución Cubana y movimientos estudiantiles en Chihuahua durante la década de 1960
}

\section{Ideological influence. The reconstruction of a concept: The Cuban Revolution and student movements in Chihuahua during the i960s}

\section{Arianna Vega Hernández* Jesús Adolfo Trujillo Holguín***}

\begin{abstract}
* Profesora de la Universidad de Sancti Spíritus (Cuba). Estudiante de la Maestría Innovación Educativa de la Universidad Autónoma de Chihuahua (México). Es Licenciada en Historia por la Universidad de Cienfuegos "Carlos Rafael Rodríguez" (Cuba). Sus temas de interés son la historia e historiografía de la educación y formación de maestros. Correo electrónico: arianna.vegagI@gmail.com
\end{abstract}

\section{(1) https://orcid.org/oooo-0002-3455-7398}

*: Profesor-investigador de la Universidad Autónoma de Chihuahua (México). Es doctor en educación y cuenta con especialidad en competencias docentes por la Universidad Autónoma de Madrid (España). Entre sus publicaciones recientes están: Debate legislativo y educación. El artículo tercero a cien años de la Constitución Política de 1917 (coord.) (20I8). Tiene reconocimiento al perfil Prodep y del Sistema Nacional de Investigadores, Nivel I. Es socio del Consejo Mexicano de Investigación Educativa, de la Sociedad Mexicana de Historia de la Educación y de la Red de Investigadores Educativos Chihuahua. Sus temas de interés son la historia e historiografía de la educación y formación de maestros. Correo electrónicojatrujillo@uach.mx

\section{http://orcid.org/oooo-0002-6738-1878}

Historial editorial

Recibido: 23-mayo-2019

Aceptado: 14.agosto-2019

Publicado: 23-septiembre-2019

ISSN-e: 2594-2956 
Influencia ideológica. La reconstrucción de un concepto: La Revolución Cubana y movimientos estudiantiles en Chihuahua durante la década de 1960

\section{Resumen}

El estudio de la influencia ideológica de la Revolución Cubana en los movimientos estudiantiles en Chihuahua es incipiente y por ello se debe indagar con dichos ejes de manera separada. Esto permitirá construir nuevos conceptos desde los diferentes aspectos de análisis. De esa forma, el presente estudio es, bajo análisis historiográfico, el resultado de la búsqueda de artículos y otros textos que realicen investigaciones similares en la actualidad, para evaluar y asumir puntos de vistas análogos y limitaciones en el estudio que aporten a la novedad e importancia de la temática. A su vez, se pretende reevaluar conceptos y reconstruirlos para asumir un constructo adecuado de influencia ideológica en este contexto, relacionándolo con los primeros hallazgos en fuentes primarias y periodísticas de la época que muestran una relación entre la recién triunfante Revolución Cubana y los movimientos de izquierda en Chihuahua. Como resultados fundamentales se obtuvieron nuevas conceptualizaciones que permiten demostrar la influencia ideológica de la Revolución Cubana en los movimientos estudiantiles de Chihuahua de la década de I960, se realizan esclarecimientos de términos importantes para el estudio como comunismo, socialismo y marxismo, y se establecen las relaciones entre ambas naciones.

Palabras Clave: Influencia ideológica, Revolución Cubana, movimientos estudiantiles 
Ideological influence. The reconstruction of a concept: The Cuban Revolution and student movements in Chihuahua during the I960s

\begin{abstract}
The study of the ideological influence of the Cuban Revolution in the student movements in Chihuahua is incipient and that is why it is necessary to investigate these axes separately. This will allow constructing new concepts from the different aspects of analysis. Thus, the present article is, under historiographical analysis, the result of the search for current articles and other texts that undertake similar studies to evaluate and assume similar points of view and limitations in the study in order to contribute to the novelty and importance of the topic. At the same time, it intends to reevaluate concepts and reconstruct them in order to assume an adequate construct of ideological influence in this context, relating it to the first findings in primary and journalistic sources of the time that show a relationship between the recently triumphant Cuban Revolution and the left movements in Chihuahua. The most significant results were new conceptualizations that allow to demonstrate the ideological influence of the Cuban Revolution in the student movements of Chihuahua in the I960s and the clarifying of important terms for research such as communism, socialism and Marxism. Finally, it was established a relevant relation for research purposes between both nations.
\end{abstract}

Keywords: Influence, Cuban Revolution, Student movements 
Influence idéologique. La reconstruction d'un concept: la révolution cubaine et les mouvements d'étudiants à Chihuahua dans les années 1960

\section{Résumé}

L'étude de l'influence idéologique de la révolution cubaine sur les mouvements d'étudiants de Chihuahua est sur le point de commencer et doit donc être examinée séparément avec ces axes. Cela permettra de construire de nouveaux concepts à partir des différents aspects de l'analyse. Ainsi, la présente étude est, sous l'analyse historiographique, le résultat de la recherche d'articles et de textes qui effectuent actuellement des recherches similaires afin d'évaluer et de supposer des points de vue et des limitations similaires qui contribuent à la nouveauté et à l'importance de l'étude. du thème. À son tour, il est prévu de réévaluer les concepts et de les reconstruire afin d'assumer une construction adéquate d'influence idéologique dans ce contexte, en le reliant aux premiers résultats des sources primaires et journalistiques de l'époque montrant une relation entre la révolution triomphante cubaine et les mouvements de gauche en place. Chihuahua En tant que résultats fondamentaux, de nouvelles conceptualisations ont été obtenues qui permettent de démontrer l'influence idéologique de la révolution cubaine dans les mouvements étudiants de Chihuahua dans les années 1960. Des clarifications sont apportées à des termes importants à étudier, tels que le communisme, le socialisme et le marxisme et des relations établies. Entre les deux pays concernés par cette recherche.

122 Mots-clés: Influence idéologique, Mouvements d'étudiants Révolution Cubaine. 
Wpływ ideologiczny. Rekonstrukcja koncepcji: rewolucja kubańska $i$ ruchy studenckie $w$ Chihuahua $w$ latach sześćdziesiątych XX wieku

\section{Streszczenie}

Badanie wpływu ideologi rewolucji kubańnskiej na ruchy studenckie w Chihuahua wydaje się uzasadnione biorc pod uwage lewackie organizaje, które w latach sześćdziesiątych istniały w Meksyku. Tego typu badania pozwalaja analizować problem z zupelnie nowej pespektywy. Do tego celu się wykorzystało rozne materiały dostępne $\mathrm{w}$ zrodłach pisanych, ktore pozwolily na reorientację badan i potwierdzenie wplywu rewolucji na Kubie na lewackie grupy mlodziezowe w Chihuahua w latach 6o-tych. Rezultatem przeprowadzonych badan jest udowodnienie jak wymieniona ideología wplynęła na lewacka partyzantkę w Chihuahua i wyjasnić róznice między komunizmem, socjalizmem i maksizmem.

\section{Slowa kluczowe:}

ideologia, rewolucja na Kubie, ruchy studenckie 


\section{Introducción}

Ampliar en el conocimiento de la historia de la educación es un reto actual. Ideal sería tener una visión holística de la misma, sin embargo, sin ver los aspectos específicos de cada región y hecho histórico, advirtiendo allí la microhistoria, sería imposible. La historia de la educación se fundamenta en conocer a sus protagonistas, ya sean docentes o estudiantes y en los procesos que estuvieron vinculados. Específicamente, los movimientos estudiantiles se han caracterizado por su posición revolucionaria, concretamente conocer más sobre la influencia ideológica de procesos representativos en estos, visto desde la historia regional en Chihuahua, aporta considerablemente a llenar vacíos de este conocimiento.

El presente artículo arroja los resultados iniciales de la búsqueda y análisis bibliográfico para el proyecto de tesis de maestría titulado: La influencia ideológica de la Revolución Cubana en los movimientos estudiantiles normalistas de Chihuahua en la década de 1960, el cual pretende vincular el triunfo revolucionario del primero de enero de I959 con el movimiento estudiantil normalista de Chihuahua. Desde una mirada particular, demostrar dicha influencia a escala nacional.

A finales de la década del 50 se desarrolla el conflicto armado que llevó al cambio gubernamental en Cuba y con ello su influencia ideológica en los movimientos sociales alrededor del mundo, y sobre

124 todo en Latinoamérica. Sin embargo, las investigaciones sobre influencia ideológica se avizoran desde diferentes matices. Por ello se considera pertinente un estudio a fondo de dicho proceso a partir de las disímiles conceptualizaciones del término, para acercarse al marco teórico metodológico de la investigación. 
Tras el triunfo revolucionario en 1959 en Cuba, una de las primeras acciones a desarrollar fue la formación ideológica, política y militar a jóvenes latinoamericanos. Aquellos que, motivados por la revolución triunfante, quisieran prepararse para llevar a sus países la semilla del Iro de enero y oponerse a los gobiernos de la época.

Autores como Robles (1977), Contreras (20II), Moulian (20I7) y Ontiveros y Pérez (20I8), coinciden en que la década del 60 fue cumbre en los movimientos sociales, principalmente estudiantiles en México. El caso de Chihuahua no se aleja de esto y hace evidente la influencia de la Revolución Cubana en este fenómeno. Desde inicios de la década de 1960 se reconocen los hechos en Cuba. Pese a que las acciones más representativas fueron las llevadas a cabo por la guerrilla chihuahuense en septiembre del 65 -en el intento de toma al Cuartel de Madera- tras la matanza, las acciones continuaron y convirtieron a toda la década en espacio de movimientos sociales y estudiantiles. Por ello la elección de esta etapa, dónde la influencia desde Cuba y el socialismo va a irradiar en el mundo.

El estudio de la influencia ideológica de la Revolución Cubana en los movimientos estudiantiles en Chihuahua es incipiente y por ello se debe indagar con dichos ejes de manera separada. Esto permitirá sustentar nuevos conceptos desde diferentes aspectos de análisis. De esa forma se trabajó con la búsqueda de artículos y otros textos que realizan estudios similares en la actualidad, para evaluar y asumir puntos de vistas análogos y limitaciones en el estudio que aporten a la novedad e importancia de la temática. A su vez, se pretende reevaluar conceptos y reconstruirlos para asumir un constructo adecuando de influencia ideológica en este contexto, relacionándolo con los primeros hallazgos en fuentes primarias y periodísticas de la 
época que muestran una relación entre la recién triunfante Revolución Cubana y los movimientos de izquierda en Chihuahua.

\section{Influencia ideológica ¿Concepto o construcción adoctrinada?}

La influencia ideológica ha sido poco trabajada como concepto específico, no siendo así el caso de influencia o ideología, que si bien, gramaticalmente unidos se asocia al término a trabajar, no constituye en sí el significado esperado. Tras la búsqueda bibliográfica se han encontrado varios estudios sobre ideología, más allá del tema político, pero hasta qué punto esta doctrina puede ser influida en otros grupos, persona, o cualquier ente social; es el punto disyuntivo en el análisis. Por lo que se plantea que en este trabajo que no se asume influencia ideológica como sinónimo de adoctrinamiento.

Algunos autores coinciden en que ideología, como concepto separado, es un término impreciso, al cual no se ha llegado a una definición exacta por las diferentes representaciones que se le ha dado en su uso. Villoro (20I5) presenta "El concepto de ideología" a partir del trabajo con fuentes documentales, realiza un análisis historiográfico donde aborda el término ideología y desde una mirada global. Según el autor:

Ideología se trataría de un término integral, interdisciplinario cuya función sería poner en relación conceptos noseológicos con conceptos sociológicos. El término ideología cumple con una función teórica doble: una función explicativa: explica las creencias injustificadas, en una forma distinta a la explicación psicológica. Y tiene una función heurística: orienta al 
investigador para descubrir un tipo de creencias injustificadas a partir del examen de su función social (Villoro, 2015, p. I4).

A partir del análisis crítico del término ideología, visto como impreciso y malinterpretado, ha sido usado con varios significados desde la teoría marxista y la sociología del conocimiento. Villoro (2015) emite el criterio de ideología como "conciencia falsa" al determinarse como "una forma de ocultamiento en que los intereses y preferencias propios de un grupo social se disfrazan, al hacerse pasar por intereses y valores universales, y se vuelven así aceptables para todos" (p.I6). A partir de lo planteado, la limitación está en asumir ideología como doctrina de engaño, pues si bien son disímiles y de intereses contrarios, las ideologías debes coincidir en sus principios para que puedan influir unas en otras.

Iñaki Moulian Jara, investigador colaborador del Museo Histórico Antropológico Maurice Van de Maele, aborda la temática desde su artículo "Bipolaridad en Chile 1960-1973", publicado en 2017. A partir del trabajo con fuentes documentales realiza el análisis histórico que permite la comparación entre las teorías que definen un mundo unipolar y las influencias ideológicas del mundo bipolar. El estudio propone un concepto a partir del precepto que:

(...) no obstante a la peculiaridad con que el conflicto bipolar se presenta en América Latina, el sentido básico va a ser el mismo; ganar "sin tocarse" una batalla que confrontaba más que a Estados, a dos percepciones ideológico-filosóficas distintas; el Capitalismo y el Socialismo. Teniendo esta confrontación continental dos formas de influenciar nuestro espacio interno; en primer lugar a través de la influencia ideológica, que se caracteriza por una conexión más bien 
intelectualizada o indirecta, y por otro lado una conexión más directa o política-táctica, que guarda relación con apertrechamiento (Moulian, 20I7, p. 4I).

El artículo, indirectamente, aporta un concepto de influencia ideológica pero limitado a su proceder, o sea al llamarla intelectualizada o indirecta, se puede asumir esta construcción como el impacto subjetivo y solapado en el país que se estudia.

El autor trabaja específicamente con la izquierda nacional de Chile influenciada por Cuba entre I960 y 1973 y específicamente la vía armada impulsada por Fidel Castro:

Así, la influencia revolucionaria de Cuba jamás se ciñó a las ideas teóricas de la revolución pacífica y por etapas implantada por la URSS, acogiendo más bien otras influencias radicales de lucha, contra la burguesía nacional capitalista y contra el imperialismo extranjero a través de las armas, táctica que se apoyaba en la construcción de un partido político-militar para la concreción de los objetivos revolucionarios y de liberación nacional contra la amenaza yankee (...) De esta manera Cuba generaba una influencia ideológica que colaboraba con la radicalización del ambiente interno, no tan sólo al mostrar a algunos jóvenes chilenos una nueva vía alternativa hacia el socialismo por las armas, sino más profundamente al plantear a los nuevos grupos políticos la premisa de la "ilegalidad del Estado" (Moulian, 20I7, p. 40).

El estudio de Moulian (2017) sirve como referente teórico para analizar la influencia de la revolución en otros países de América Latina. El modus-operandi de la política exterior cubana fue similar en 
muchos países del mundo, sobre todo del continente y fue asumido por los diferentes movimientos sociales que se gestaban en el área. Sin embargo, el estudio carece de un análisis exhaustivo que represente las líneas temáticas que permitas caracterizar la influencia ideológica, a pesar de ellos, sí integra dentro del concepto la posición militarista y la creación de partidos políticos como semejanza de la triunfante Revolución en Cuba.

Desde el punto de vista de la relación con el tema que se trabaja en este proyecto, el artículo "La influencia de la Revolución Cubana en el imaginario de las derechas política y mediática, I958-I962", de la investigadora chilena Castro (20I4), es relevante. Este estudio considera el análisis de las construcciones realizadas a un nivel discursivo por las derechas respecto del rechazo al comunismo. La investigación pertenece a un programa académico que busca generar un espacio de conocimiento, opinión y reflexión sobre las ideas políticas que influyen y conforman el debate y la esfera pública, así como su presencia en los diseños institucionales del país, durante los siglos XIX y XX.

El estudio anterior aporta como fuente para comparar un análisis de la influencia de la Revolución Cubana en otro país latinoamericano. Permite visibilizar desde perspectivas continentales cómo ha sido vista y se ha desarrollado la influencia ideológica, pero esta vez no por los influenciados, sino por los contrarios a este.

A modo de resumen, es posible observar que antes de que ocurriese la Revolución Cubana, predominaba una imagen inminentemente positiva respecto al proceso, ya que no parecía que fuesen a instaurar un régimen comunista $\mathrm{y}$ destacaban el carácter "liberador" del movimiento de Castro. 
En efecto, se priorizó el derrocamiento de Batista, a pesar de que se tratase de una dictadura de derecha, lo cual implica que durante ese período tampoco se esperaba que a futuro se impusiera un gobierno comunista. Si bien, el factor determinante del cambio en el imaginario de las derechas fue la propiedad, el tema político siempre fue importante, y fue el segundo factor determinante para cambiar la imagen que se tenía respecto a Cuba (Castro, 20I4, p. I7).

Cabe destacar que los argumentos usados no cambiaron sustancialmente durante los años de estudios, ya que se exponía continuamente que el comunismo era equivalente a un régimen tiránico o dictatorial, también se intentaba desacreditar su sistema exhibiendo que era poco eficiente y que se aprovechaban de ciertas libertades para sus propios fines. Vale decir que las ideas expuestas fueron más categóricas e incluyeron el tema bélico durante 1962 por la conocida crisis de Octubre o de los misiles, al instalar en Cuba armas nucleares soviéticas y el retiro de las mismas por la amenaza de una Tercera Guerra Mundial por parte de los Estados Unidos.

La revisión realizada permite ver la influencia ideológica desde varias teorías y para diversos usos. Sin embargo, asumiendo la diversidad de criterios se observa que desde cada postura se le da un significado como construcción adoctrinada, de la cual este estudio no podrá separase por el hecho de la subjetividad y la formación del investigador y de las fuentes a consultar. En sí como concepto se asume para la presente influencia ideológica como la tendencia a conservar o a transformar el sistema social, económico, político o cultural existente. Es decir, reflexiona sobre cómo actúa la sociedad en su conjunto y, en base a eso, elabora un plan de acción para acercarse a lo que considera como la sociedad ideal. Por supuesto 
siempre va estar permeado por su carácter de herramienta de control social.

\section{Ideología: un concepto necesario}

Para determinar si existe influencia de tipo ideológica en algún proceso, hecho histórico, o grupo social, es necesario conocer lo que el vocablo ideología plantea. Puede decirse que todo hombre tiene una ideología, como concepción del mundo, la cual orienta a los seres humanos en su práctica diaria. El término incluye varias esferas, tanto para un individuo como para un grupo social, pueden ser religiosa, política, artística, entre otras. El sujeto debe tener una ideología política, que puede llegar a sí por estudios, formación social, escolar o familiar. El término, visto desde diferentes ciencias o áreas disciplinarias, cambia su significación o uso, según Verón (I97I):

En cuanto al estudio de las ideologías, difícilmente podrá hallarse en la sociología otro campo con una tradición intelectual más venerable y mayor confusión conceptual [...] las ciencias sociales no han desarrollado todavía una auténtica concepción no evaluativa de la ideología [...] Si bien el término ideología fue introducido en forma sistemática con bastante anterioridad, su sentido más popularizado en la literatura deriva sobre todo de la influencia del marxismo (p. 13).

Es necesario para el presente estudio, un acercamiento al origen del término y sus acepciones. Se busca la creación de un concepto que permita justificar si hubo influencia ideológica de la Revolución Cubana en movimientos sociales en la época. 
La historiografía recoge el término ideología desde las más disímiles concepciones. Varios filósofos han mostrados contradicciones sustantivas en este tema, entre ellos Karl Marx y Louis Althusser. El hecho de ser mecanismo de control o no, si tiene o no relación con la historia, o el funcionamiento o no de la misma, son temas recurrentes que hacen conflictivo el término. "La ideología no es manipulación como lo creía Marx (cosa que aún sigue en las cabezas de muchas personas en diversos sectores sociales y académicos), sino que es construcción del sujeto" (Mora, 20I2, p. 5). Existen en la actualidad estudios que reflejan la ideología como medio de dominación, otros defienden un uso positivo e indispensable. Para llegar a un consenso se deben analizar varias posturas para la elaboración de un concepto propio que sustente la presente investigación.

Referido a la temática a abordar, se aleja considerablemente la posibilidad de manipulación, pues se trabaja con temas de aceptación y toma guía de un modelo para lograr cambios sociales y de sistema. Se interesa este trabajo en localizar los aspectos que convierten en común modus- operandi, discursos políticos e ideología entre lo sucedido en Cuba a partir del triunfo revolucionario y el accionar de los movimientos normalistas en Chihuahua de la década de I960.

A partir de la búsqueda en fuentes primarias, cómo la prensa de la época, se localizó en el periódico "El Heraldo" que casi a diario se tocaba durante toda la década el tema de Cuba. Atendiendo a los

132 intereses y posicionamiento político de este periódico, la Revolución Cubana se satanizaba. Pese a ello y la dominación ideológica que puede ejercer un medio de prensa tan importante en la ciudad, grupos de estudiantes, intelectuales y campesinos, eran influenciados por el proceso cubano a partir de sus propias creencias y necesidades sociales. 
Algunos de los titulares de dicho periódico en la etapa a estudiar revelan la posición y el interés de hacer ver a Cuba como una amenaza para el territorio. "Apoyo armado para exportar el Comunismo desde Cuba cautiva" (ver imagen I) y "Bombardeaos Soviéticos y proyectiles, Cuba es base para extender el imperialismo Rojo" son las primeras planas de El Heraldo el I de enero de 1962. En las mismas se hace alusión a la situación en Cuba y su política de extender el sistema social en la región, además de las primeras noticias de la crisis porvenir de los misiles. El 3 de enero del propio año, dicho medio de prensa publicaba como titular en la página I "Agentes Comunistas disfrazados de sacerdotes y de Anticomunistas" y "Con aviones y lanzacohetes Soviéticos Castro festejó el aniversario de la entrega de Cuba al comunismo". Un día después las portados de los periódicos continuaban con "Cuba es Tierra Soviética; Excomunión de Castro Ruz" y "El propio Fidel es ya cautivo del Comunismo"

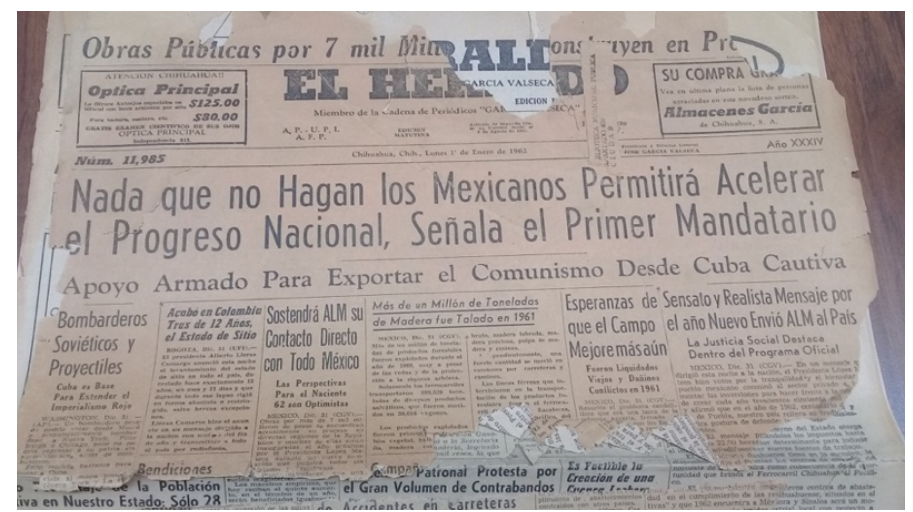

Imagen I. Portada de El Heraldo de Chihuahua del I de enero de 1962 (AHM, 1962). 
Estas notas informativas se encargaban de dar a conocer al pueblo chihuahuense la amenaza de Cuba para el continente y para los Estados Unidos ya que mencionaba "WASHINGTON: en Departamento de Estado reveló hoy que Cuba recibió entre sesenta y cien millones de dólares en ayuda militar del bloque soviético, lo cual lo convierte en la segunda potencia terrestre del hemisferio, después de los Estados Unidos" (El Heraldo, I962, abril I, p. I). Se intentaba además satanizar y vender una figura de los líderes cubanos alejados de la religión, en un pueblo tan creyente y seguidor de estas doctrinas "Ciudad del Vaticano: el Primer Ministro Cubano Fidel Castro, ha sido excomulgado por la Iglesia Católica, según dijo hoy el Vaticano (...)” (p. 4). ¿Hasta qué punto entonces, se recibía influencia ideológica cómo medio de dominación, cuando el vocero del poder en Chihuahua alejaba dichas doctrinas desmoralizándolas?

Según la concepción de Marx, iniciador del concepto, la ideología es un producto falso que se va construyendo a partir de la división social del trabajo:

La moral, la religión, la metafísica y cualquier otra ideología y las formas de conciencia que a ellas corresponden pierden, así, la apariencia de su propia sustantividad. No tienen su propia historia ni su propio desarrollo, sino que los hombres que desarrollan su producción material y su intercambio material cambian también, al cambiar esta realidad su pensamiento y los productos de su pensamiento (Marx, 2000, p. 28).

A partir de este estudio, la ideología es una ilusión, un mal sueño, del que la consciencia debe despertar por medio de la ciencia, de ahí la importancia por hacer del materialismo histórico, y del comunismo, ciencias con todas sus letras (Mora, 2012). En general, la ideología 
para Karl Marx es un método de engaño con el cual la superestructura mantiene a la infraestructura realizando el supuesto trabajo material, por tanto no existe, ni contiene valor real. Pese a los puntos que tiene a su favor esta teoría por el uso indiscriminado de ideologías para someter grupos sociales, se pude enfrentar a otras para llegar a conceptos más apegados a la realidad.

Otro punto a tener en cuenta es que las ideologías pueden ser asumidas por los grupos sociales, como se pretende investigar en este estudio. Por ello, en el caso de la Revolución Cubana, más allá de manipular, puede constituir un ejemplo para ciertos grupos o sectores sociales que tuviesen los mismos móviles para el apego a dicha ideología.

Por analizar conceptos de la terminología a abordar se utiliza la obra de Louis Althusser, teórico marxista con método estructuralista, quien conceptualiza que: "La ideología es la 'representación' de las relaciones imaginarias de los individuos con sus condiciones reales de existencia" (Althusser, 1970, p. 52). Para el autor es aquello que une al sujeto imaginariamente con sus condiciones materiales de existencia, una explicación o justificación de por qué vive como vive. Louis Althusser relaciona el término con aquellos Aparatos Ideológicos de Estado (AIE) para el convencimiento más allá de la violencia, a partir de las familias, la escuela, la iglesia, los medios de comunicación, entre otros, para reproducir la ideología dominante.

Sin embargo, la ideología política de la que se habla en este estudio proviene de las clases sociales más desfavorecidas. Ello hace que, en coincidencia con lo planeado por Althusser, las condiciones reales de su existencia llevasen a estos movimientos estudiantiles a asumirla. Para apoyar este planteamiento se debe ahondar además en que, los 
estudiantes normalistas estaban muy vinculados a las realidades rurales del Estado de Chihuahua, y por ello entendían y se solidarizaban con las demandas de este sector.

Otro tema a recurrir es la relación historia- ideología. El dilema de la existencia de una sin la otra donde una vez más los disímiles criterios amplían el basamento teórico y lo complejizan.

A saber, para Marx la ideología no tiene historia. No la tiene porque la historia es una ciencia concreta que debe hablar sobre las formaciones reales concretas de grupos sociales. Quizá sin ser tan claro, Marx expone su desacuerdo con la historia de su tiempo y de su Alemania; una historia de las ideas que condiciona y ordena los acontecimientos con relación a las mismas; una historia ideológica pues, separada de la ciencia real (Mora, 20I2, p. II).

Si bien es indudable el hecho de que la historia es una ciencia, la cual está dotada de objeto de estudio y la cual debe estar comprometida con la realidad, apelando a la subjetividad de quienes la hacen, quienes la investigan, quienes la escriben y quienes la interpretan, si definen ideologías y posicionamientos con cargas ideológicas, intencionales o no.

Althusser, sin embargo, piensa la ideología como la responsable de interpelar a los individuos como sujetos. De esta forma pasa de ser solo ideas irreales, a ser prácticas sociales materiales de allí su ambigüedad de que la ideología, tiene y no tiene historia:

Por una parte puedo sostener que las ideologías tienen una historia propia (aunque esté determinada en última instancia 
por la lucha de clases); y, por otra, puedo sostener al mismo tiempo que la ideología en general no tiene historia, pero no en un sentido negativo (su historia está fuera de ella), sino en un sentido totalmente positivo. Este sentido es positivo si realmente es propio de la ideología el estar dotado de una estructura y un funcionamiento tales que la constituyen en una realidad no-histórica, es decir omnihistórica, en el sentido en que ese funcionamiento, bajo una misma forma, inmutable, están presentes en lo que se llama la historia toda, en el sentido en el que el Manifiesto define la historia como historia de la lucha de clases, es decir, como historia de las sociedades de clases (Althusser, I970, p. 50-5I).

Por ello la ideología tiene historia dependiendo de las sociedades a analizar como es el caso que ataña esta investigación, y la representatividad de ella. El triunfo de la Revolución Cubana significó para el mundo, sobre todo el continente americano, una esperanza o modelo de cambio, para unos y una amenaza para otros. Es posible rastrear la historia de una ideología en un proceso, etapa o región, sin embargo el carácter eterno de la ideología hace que no tenga historia.

La funcionalidad de la ideología para Marx es nula. A dicho criterio se contrapone Althusser definiendo que, la función de la ideología es reproducir las relaciones de producción de la manera menos violenta posible. Al contrario de Karl Marx, este no habla de dominación de la clase, sino de formación del sujeto, de ahí la necesidad o funcionalidad de la ideología (Mora, 20I2). Sin embargo, en este caso también se aleja del concepto a conformar, ya que fue la violencia uno de los medios a utilizar por dichos movimientos en Chihuahua, y ello 
pudo haber sido influido por la ideología que llegaba desde Cuba y los resultados iniciales de su proceso revolucionario.

Los planteamientos analizados permiten sustentar el hecho que una ideología puede ser transmitida, enseñada o influenciada, y no con ello se asume que sea por dominar o esclavizar. Estos autores afirman la positividad de la ideología y la indudabilidad de su existencia. Puede ser, como dijo Marx, un engaño que la superestructura de la clase dominante impone para engañar a la infra- estructura, según el sistema social que impere. Pero también puede ser una forma concreta y material de vida que representa las relaciones de producción.

También se define ideología

[...] como la visión del mundo de un grupo social, a su propia práctica, al institucionalizar sus sentidos de la realidad y transformarse en similar a los otros, en el aprendizaje de los diferentes valores culturales a través de las distintas generaciones (Ruiz y Estrevel, 2008, p. I84).

A partir de la anterior definición, se visualiza cómo una ideología puede ser también asumida por otros grupos sociales de manera voluntaria. Este sería el caso de los movimientos sociales en México ante el triunfo revolucionario cubano en enero de 1959.

Sobre la influencia ideológica de la Revolución Cubana, se determina que ha sido de manera directa e indirecta. Según Moulian (200I), esta no se constriñó a las ideas teóricas pacíficas y por etapas implantada por la URSS. Fueron más, influencias radicales de lucha contra la burguesía nacional capitalista y contra el imperialismo extranjero. 
Hubo en ciertos países latinoamericanos envío de armas y exportación de tácticas que se apoyaban en la construcción de partidos político-militar para la concreción de los objetivos revolucionarios y de liberación nacional. A partir de lo mismo Ernesto Che Guevara enuncia en Tricontinental, Suplemento especial del I6 de abril de I967, que:

La finalidad estratégica de esa lucha debe ser la destrucción del imperialismo [...] El elemento fundamental de esa finalidad [...] será [...] la liberación que se producirá, a través de la lucha armada, en la mayoría de los casos, y que tendrá en América casi indefectiblemente la propiedad de convertirse en una revolución socialista (Guevara, 1977, p. 36).

Ante la realidad del conflicto bipolar que se presenta en Latinoamérica a partir del triunfo revolucionario de I959, se visibilizó la oposición entre dos percepciones ideológico-filosóficas distintas; el Capitalismo y el Socialismo. Se puede identificar, teniendo esta confrontación continental dos formas de influenciar la política cubana en el hemisferio. Primero a partir de la influencia ideológica, que se caracteriza por una conexión más bien intelectualizada o indirecta, y por otro lado una conexión más directa o política-táctica, que guarda relación con apertrechamiento militar o ayuda económica (Moulian, 200I).

Asumiendo el análisis de las teorías antes mencionadas y llevando al contexto que pretende la presente investigación, asumimos ideología como condicionada por los intereses sociales. Ella orienta la acción de los hombres permitiéndoles mayores o menores posibilidades para acercarse al conocimiento objetivo de la realidad social. A partir de ella los grupos sociales exponen sus condiciones de vida y luchan 
por cambiarla o mantenerla. La ideología guía y justifica un comportamiento práctico de los hombres acorde con esos intereses, aspiraciones o ideales.

La influencia ideológica, por su parte, es la exportación de ideales y la postura que asume el hombre respondiendo a sus intereses. Puede presentarse de manera directa o indirecta, o sea ser enseñada o puede ser asumida por las condiciones reales de vida, similares a otros procesos que comparten dichas posturas ideológicas. Estas a su vez, influyen en mayor o menor medida en el surgimiento, contenido y uso de los conocimientos sociales.

\section{Algunas categorías conceptuales de obligatoria consulta: Socialismo, Comunismo, Marxismo}

Para determinar la influencia ideológica de la Revolución Cubana en los procesos históricos ocurridos en México durante la década de I960 es necesario conocer cuál era dicha ideología y cómo se fue desarrollando. La Constitución de la república de Cuba reconoce en su Artículo primero que: "La República de Cuba es un Estado socialista de obreros y campesinos y demás trabajadores manuales e intelectuales". Por su parte el Artículo 5 enuncia:

El Partido Comunista de Cuba, vanguardia organizada marxista-leninista de la clase obrera, es la fuerza dirigente de la sociedad y del Estado, que organiza y orienta los esfuerzos comunes hacia los altos fines de la construcción del socialismo y el avance hacia la sociedad comunista (Asamblea Nacional del Poder Popular, 1976). 
Si bien, legalmente el carácter socialista de la Revolución Cubana no se dicta hasta el 24 de febrero de 1976 con la Constitución, la ideología se había instituido desde mucho antes. Se podría hablar desde la formación marxista-leninista de los principales líderes de la Revolución Cubana, o desde el Programa del Moncada. Sin embargo, fue a partir del I6 de abril de 196I, cuando el Comandante en Jefe Fidel Castro Ruz, en las honras fúnebres de las víctimas del bombardeo a distintos puntos de la República de Cuba, enuncia:

Compañeros obreros y campesinos: esta es la revolución socialista y democrática de los humildes, con los humildes y para los humildes. Y por esta revolución de los humildes, por los humildes y para los humildes, estamos dispuestos a dar la vida (Noval, 200I p. 3).

Los términos marxismo, socialismo o comunismo no se habían manejado por el joven gobierno triunfante, pero sí era parte de la ideología de sus gestores y por ello constituyen terminologías de obligatoria consulta para el presente estudio. Son disímiles las acepciones que se pueden trabajar de dichas categorías conceptuales.

Como es deducible, el marxismo constituye una doctrina que tiene sus bases en las teorías de Marx y Engels. Dentro de las mismas, distinguen la creación de una sociedad sin distinción de clases. Aquellas organizaciones seguidoras de estas doctrinas se reconocen como marxistas. En el caso cubano, muchos fueron los jóvenes seguidores y estudiosos de dichas teorías. En el caso específico de Fidel Castro fue partidario y crítico de esta postura. Sobre este tema ahondó Fidel Castro, el to de abril de 1963, al pronunciar un discurso en las conclusiones del Primer Congreso Nacional de Maestros de 
Vanguardia "Frank País", conjuntamente con el acto de graduación de las EBIR:

Quizás una de las cosas, sin embargo, más difíciles de comprender es que ninguna de esas interpretaciones son interpretaciones mecánicas, que ninguna de esas interpretaciones tienen que ser interpretaciones de cliché, y que el marxismo no es un conjunto de "formulitas" para tratar de aplicar a la fuerza la explicación de cada problema concreto, sino una visión dialéctica de los problemas, una aplicación viva de esos principios, una guía, un método (Heredia, 20I5, p. I2).

Teorizar sobre esta doctrina resulta complejo de verse como modo rígido para su aplicación. Al decir de varios analistas reconocidos, entre ellos Fidel, el marxismo es un procedimiento y a su vez es cambiable según los intereses y el momento histórico. Relacionado a la Revolución Cubana enunció:

[...] el marxismo no es solo la única verdadera ciencia de la política y de la revolución, sino que desde que el hombre tiene conciencia de sí mismo, es la única interpretación verdadera del proceso de desarrollo de la historia humana [...] Pero nosotros no estudiamos marxismo por simple curiosidad filosófica o histórica. No. Para nosotros es vital, es fundamental, es decisivo, estudiar marxismo y enseñar marxismo: para la Revolución es vital y es decisivo estudiar marxismo y enseñar marxismo (Castro, 1962).

A partir del desarrollo de dicha doctrina emana como corriente de pensamiento el socialismo. Este constituyó en Latinoamérica un 
modelo muy fuerte a estudiar y a seguir por los sectores más radicales. El socialismo es visto como paso antecesor para el comunismo.

El comunismo en toda la extensión de la palabra buscaba la definición de un Estado ateo, la colectivización de los medios de producción, la igualdad de clases, el ascenso al poder del proletariado mediante la revolución y otros principios que demostraron su falta de viabilidad en todos los países que adoptaron al socialismo como forma de gobierno (Trujillo, 20I5, p. I08).

El acercarse a estos conceptos que permearon en el ideal de la Revolución Cubana, tanto en el proceso de su conformación y establecimiento como en su posterior desarrollo, permite su mejor comprensión. Las ideas socialistas, comunistas, o el marxismo en sí, no eran ideas nuevas para el México de la década de 1960. Los jóvenes y estudiantes heredaban un profundo conocimiento de estas doctrinas desde los años 40, de fuerte arraigo izquierdista en el país. Sin embargo, basados en estos, la influencia de la Revolución Cubana fue más fuerte y profunda en los movimientos estudiantiles normalistas de la época.

\section{Teorías explicativas de ideología en la Cuba socialista}

Sería imposible explicar la influencia ideológica de la Revolución Cubana sin tener puntos centrales acabados sobre su doctrina. Aspectos fundamentales que cimientan la historia del proceso revolucionario y su política capaz de llevar la bipolaridad al continente latinoamericano. El gobierno cubano y su ideología 
reconocen la historia de la revolución como única desde el io de octubre de I868, por constituir una continuidad del proceso independentista, en busca de la soberanía nacional. Ello hace visible que la influencia cubana hacia el mundo vaya desde los principios hasta las técnicas de lucha para lograr la victoria de enero de 1959. La preparación de jóvenes revolucionarios, la toma de la segunda fortaleza militar más importante del país, la preparación en el exilio, la guerra de guerrilla, fueron modelos asumidos por nacientes grupos revolucionarios en el continente.

La ideología del grupo revolucionario que llevó a cabo el asalto al Cuartel Moncada el 26 de julio de 1953, la Generación del Centenario o movimiento, deja sentadas sus bases ideológicas en el Programa o Manifiesto del Moncada. Este da a conocer el objetivo de la lucha y de la acción en particular, que era tomar las armas para dirigirse apertrechados a la Sierra Maestra, sede dónde iniciaría la lucha armada a la que se uniría todo el pueblo (Civeira y Loyola, 1998). Deja en claro el carácter antiimperialista y revolucionario de grupo rebelde.

Ante el fracaso de esta acción se reitera el posicionamiento el i6 de octubre de 1953 en el juicio de Fidel Castro, quien solicitó su autodefensa, y allí se pronunció "La Historia me Absolverá", que de inmediato se convirtió en el programa político del movimiento revolucionario. Dicho documento denuncia los turbios manejos del 144 proceso judicial. Además, sintetiza la lamentable realidad cubana de aquellos momentos en lo económico, político y lo social y se consignan las leyes revolucionarias que inicialmente habrían de dictarse, una vez logrado el triunfo. Declara que la política cubana en América sería de estrecha solidaridad con los pueblos democráticos y el amparo a los perseguidos políticos. Adelanta una serie de leyes y 
medidas que serían aplicadas después de triunfo como: la reforma agraria, la reforma integral de la enseñanza, la nacionalizaciones, entre otras (Civeira y Loyola, 1998).

Desde ese momento, ya era visible la ideología de los jóvenes y la preparación en temas políticos, que profundizó durante el periodo de prisión y el exilio. Desde allí, el ya Movimiento 26 de Julio, planea la ofensiva contra el gobierno de Cuba y se inicia la lucha en el año I956. Dicho proceso llevó al triunfo de la Revolución el I ${ }^{\circ}$ de enero de I959, que destruye lo que quedaba del gobierno anterior y comienza todo un proceso de transformaciones revolucionarias en el país.

Después de cumplir las tareas correspondientes a la etapa nacional liberadora o etapa popular agraria y antimperialista de la Revolución, sobreviene un período caracterizado por tareas y soluciones que van más allá del cumplimiento del programa del Moncada en el que las nacionalizaciones, llevadas a cabo en octubre de i960, marcaron el rumbo definitivo y la incompatibilidad de la Revolución con cualquiera de las formas de explotación (Civeira y Loyola, 1998).

Tal proceso de expropiación del capital extranjero provocó la política ofensiva del imperialismo, demostrada en el la contrarrevolución interna, el fomento de bandas armadas, las constantes agresiones como la de Playa Girón y otras. Este elemento unido a las condiciones históricas imperantes en el momento en que se produce el triunfo, contribuyeron a acelerar el tránsito de la revolución democrática a la socialista en Cuba.

Primeramente se debe considerar que dicho tránsito se lleva a cabo en un período breve de tiempo. Ya hacia octubre de 1960 se desarrollaban las nacionalizaciones antimperialistas y socialistas que marcaron ese rumbo, al eliminar con ello la propiedad privada sobre 
los principales medios de producción y las posibilidades de explotación. También hay que tener presente que las tareas de la etapa nacional liberadoras y las socialistas se desarrollan bajo una misma dirección. El problema del poder político había sido resuelto desde los primeros momentos, pues aunque existió un gobierno provisional, el verdadero poder estaba representado en el Ejército Rebelde con la conducción de Fidel Castro (Civeira y Loyola, 1998).

No existió una barrera entre las tareas nacionales liberadoras y las tareas socialistas. Ambas formaron parte de un proceso único, continuo e ininterrumpido en el que, en ocasiones, las medidas de carácter democrático tenían ya un matiz socialista y prepararon el terreno para las transformaciones netamente socialistas. El elemento decisivo y definitorio de este proceso es la cuestión de quienes lo dirigen y en manos de quien está el verdadero poder.

Con el fin de caracterizar los años sesenta en Cuba se estudia a Martínez Heredia, uno de los pensadores cubanos que más ha abordado el tema de la ideología cubana. Este autor:

[...] define la Revolución como socialista de liberación nacional, como un proceso contradictorio en que se sintetizan los ideales socialistas y nacionalistas del pueblo cubano. Por ello, concibe el socialismo cubano como una expresión particular, que tiene como esencia el patriotismo radical, un socialismo que se situaba en el centro de la liberación nacional [...] No obstante, distingue la etapa de mayor auge de ese patriotismo radical (1959-196I) de la etapa en que el marxismoleninismo comenzó a tener fuerza masiva (a partir de I96I), con una lectura propia, nacional - lo que, choca con la 
ideología teorizada soviética y con el pensamiento cubano afín a aquella (Martínez en Alemán, 2013, pp. I70-171).

La anterior cita permite conceptualizar el término de Revolución para el caso cubano y su relación con el socialismo. De esta manera se resumen las teorías fundamentales que explican la ideología de la Revolución Cubana, comenzando por el carácter histórico de la revolución y por un proceso ideológico fundamentado en la preparación marxista-leninista de sus dirigentes, sin olvidar los programas nacionalistas y un socialismo autóctono y ajustado a la realidad cubana de entonces.

\section{Relación entre Cuba y México: un acercamiento indispensable}

En la introducción del libro "Los informantes", del doctor Javier Horacio Contreras Orozco, se hace alusión a la relación entre ambos países con respecto a la preparación de la lucha insurreccional en Cuba.

[México] era el país con que el gobierno socialista de Cuba estaba muy agradecido desde que habían dado trato preferencial a Fidel Castro, cuando fue sorprendido y detenido en sus actividades de preparación para la toma del cuartel militar en Cuba y derrocar el gobierno de Fulgencio Batista. Castro nunca olvidaría que el jefe de la policía política de México, lo había tratado de manera especial (Contreras, 20II, p. I6).

Lo cierto es que estos vínculos se acrecentaron con el triunfo en 1959. Una de las primeras tareas de la Revolución Cubana fue brindar 
preparación táctica, ideológica y militar a los jóvenes que querían llevar el sistema social de izquierda a los países de Latinoamérica. Algunas fuentes consultadas refieren la presencia en Cuba de algunos líderes de los movimientos e incluso sus familiares para el exilio, luego de los sucesos de 1965 en Madera, Chihuahua. Estos datos se deben verificar durante la investigación.

El México de los años 60 fue hervidero de movimientos sociales y estudiantiles. Hechos como los de octubre del 68 lo demuestran. Chihuahua también tuvo su máxima expresión de rebeldía durante esa etapa con la formación de guerrillas, acciones armadas y la participación del estudiantado. Dichos movimientos fueron influidos tanto por la corriente de acciones del resto del mundo como la ascendencia de socialismo y el triunfo revolucionario en Cuba. A partir de este estudio en la región de Chihuahua se podrá ampliar para el resto del continente.

Algunos autores consultados abordan la temática desde diversas perspectivas. En el caso de la literatura cubana, textos como Breve historia de la Revolución Cubana o Cuba y su historia, de autores como Civeira y Loyola (I998), trabajan los hechos significativos que dieron paso al triunfo, entre ellos, la estancia de los moncadistas en México y el apoyo de este país. Además, tratan los elementos de solidaridad hacia los movimientos de izquierda de Latinoamérica. Sin embargo, solo llega hasta la mención y no en si a la repercusión o 148 influencia ideológica en estos.

Con respecto a la relación entre ambos países, autores como Espinosa (20II) y Pantojas (20II) abordan la proyección de México en Cuba a través de la historia. Estos estudios permiten relacionar la trayectoria de ambos países de manera cronológica para sustentar que son 
pueblos que han luchado juntos y se han apoyado en disímiles procesos, independientemente del posicionamiento político de sus gobernantes. Sin embargo, no interactúan en el período escogido para la presente investigación.

Otro caso relevante es el libro de Miguel Ángel Parra Orozco "Madera 73. Vida de una región chihuahuense" que sale a luz en I973, año muy cercano al periodo seleccionados para este estudio. A pesar que el texto es la narrativa histórica del poblado de Maderas desde su fundación hasta 1973, representa un documento valioso pues su autor era egresado de la Escuela Normal del Estado en 1962 y por ende su visión es portadora de los criterios de los estudiantes normalistas en la etapa. Se hace en el texto un recuento de los hechos de 1965 y se toca la influencia cubana. Este puede ser asumido como fuente primaria, al ser testimonio de la época.

La relación entre ambas regiones a analizar permite demostrar la existencia de influencia en procesos históricos diferentes. Especialmente el lapso de tiempo a estudiar, dónde acontecieron movimientos sociales importantes en Latinoamérica, permiten fundamentar que el aliento a la izquierda en la región pudo estar influida por la joven triunfante Revolución Cubana. Ambos países, históricamente relacionados, una vez más tienen puntos en común por ser seguidores, en esta época de una ideología y tácticas similar.

\section{9}

\section{Conclusiones}

La influencia ideológica se asume como la tendencia a conservar o a transformar el sistema social, económico, político o cultural existente. Está condicionada por los intereses sociales. Orienta la 
acción de los hombres permitiéndoles mayores o menores posibilidades para acercarse al conocimiento objetivo de la realidad social. A partir de ella, los grupos sociales exponen sus condiciones de vida y luchan por cambiarla o mantenerla. La ideología guía y justifica un comportamiento práctico de los hombres acorde con esos intereses, aspiraciones o ideales. Se entiende entonces la influencia de la Revolución Cubana a los movimientos estudiantiles de Chihuahua de manera indirecta y asumida por sus protagonistas.

La influencia ideológica, por su parte, es la exportación de ideales y la postura que asume el hombre respondiendo a sus intereses. Puede presentarse de manera directa o indirecta, o sea ser enseñada o puede ser asumida por las condiciones reales de vida similares a otros procesos que comparten dichas posturas ideológicas. Estas a su vez, influyen en mayor o menor medida en el surgimiento, contenido y uso de los conocimientos sociales.

Las ideas socialistas, comunistas o el marxismo en sí, no eran ideas nuevas para el México de la década de 1960. Los jóvenes y estudiantes heredaban un profundo conocimiento de estas doctrinas desde los años 40, considerados de fuerte arraigo izquierdista en el país. Sin embargo, basados en estos, la influencia de la Revolución Cubana fue más fuerte y profunda en los movimientos estudiantiles normalistas de la época.

\section{Referencias}

AHM. (I962). El Heraldo de Chihuahua del I de enero de I962. Archivo Histórico Municipal, Chihuahua, México. 
Alemán, Y.M.(2013). La función ideológica de la historiografía cubana en la década del sesenta del siglo XX. Latin American Research

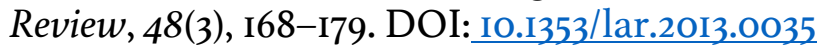

Althusser, L. (1970). Ideología y aparatos ideológicos de estado. 8va Ed. México: Quinto Sol.

Asamblea Nacional del Poder Popular. (1976). Constitución de la República de Cuba. La Habana.

Castro, F. (1962, junio 27). Discurso. Resumen de la reunión con los directores de Escuelas de Instrucción Revolucionaria. La Habana, Cuba.

Castro, J. (20I4). La influencia de la Revolución Cubana en el imaginario de las derechas política y mediática, I958-I962 [Documento de Trabajo $\mathrm{N}^{\circ}$ 5, Programa de Historia de las Ideas Políticas en Chile]. Chile: Universidad Diego Portales.

Civeira, F.L.; y Loyola, O. (1998). Cuba y su Historia. La Habana: Gente Nueva.

Contreras Orozco, J.H. (20II). Los Informantes. Documentos confidenciales de la guerrilla en Chihuahua. Chihuahua, México: Universidad Autónoma de Chihuahua.

Espinosa, M. (20II). La proyección de México en Cuba: La estela del artilugio I886-I9Io. Michoacán, México: Instituto de Investigaciones Históricas / Universidad Michoacana de San Nicolás de Hidalgo.

Guevara, E. (1977) Escritos y Discursos. Tomo 9. La Habana, Cuba: Editorial de Ciencias Sociales. 
Heredia, F. (2015, mayo 5). Marx 200: ¿Qué pensaba Fidel sobre el Genio de Tréveris?. En Fidel Soldado de Ideas. Recuperado de: http://www.fidelcastro.cu/es/articulos/marx-200-quepensaba-fidel-sobre-el-genio-de-treveris

Marx, K. (2000). La ideología alemana. México: Quinto sol.

Mora, F. (2012). Ideología. Un estudio sobre la teoría de Louis Althusser. México: Universidad Nacional Autónoma de México.

Moulian Jara, I. (200I). Bipolaridad en Chile I960-I973. Revista Austral de Ciencias Sociales, (5), 39-52. DOI: I0.4206/rev.austral.cienc.soc.200I.n5-04

Noval, L. (200I). Fidel Castro y el carácter socialista de la Revolución Cubana. Cuba Debate, 7-8.

Ontiveros Juárerz, G.; y Pérez Piñón, F. A. (2018). Balances y aproximaciones teóricas al movimiento estudiantil. Debates por la Historia, 6(I), 39-64. Recuperado de: https://vocero.uach.mx/index.php/debates-por-lahistoria/article/view/9

Pantojas García, E. (20I4). Las dos grandes revoluciones del Caribe, Haití y Cuba: ¿Ejemplos o escarmientos? América Latina Hoy, (66), I69I80.

Robles, M. (I977). Educación y Sociedad en la Historia de México. México: Siglo Veintiuno Editores.

Ruiz Carrillo, E.; y Estrevel Rivera, L.B. (2008). Construcción del sujeto e ideología Social. Tiempo de Educar, 9(I8), I83-I98. Recuperado de: http://www.redalyc.org/pdf/3II/3IIIIIIOO2.pdf 
Trujillo Holguín, J.A. (2015). La educación socialista en Chihuahua 19341940, una mirada desde la Escuela Normal del Estado. Chihuahua, México: Universidad Autónoma de Chihuahua.

Verón, E. (197I). Ideología y comunicación de masas: La semantización de la violencia política. VV.AA. Lenguaje y comunicación social, I3(4), I2-I8. Recuperado de: http://www.periodismo.uchile.cl/talleres/teoriacomunicacion larchivos/veron.pdf

Villoro, L. (2015). El concepto de ideología. México: Fondo de Cultura Económica.

Este artículo se publica bajo una licencia de Creative Commons Reconocimiento-NoComercial 4.0
Internacional, y puede ser usados gratuitamente para fines no comerciales, dando los créditos a los
autores y a la revista.

